\title{
Ehrenfried Zschech
}
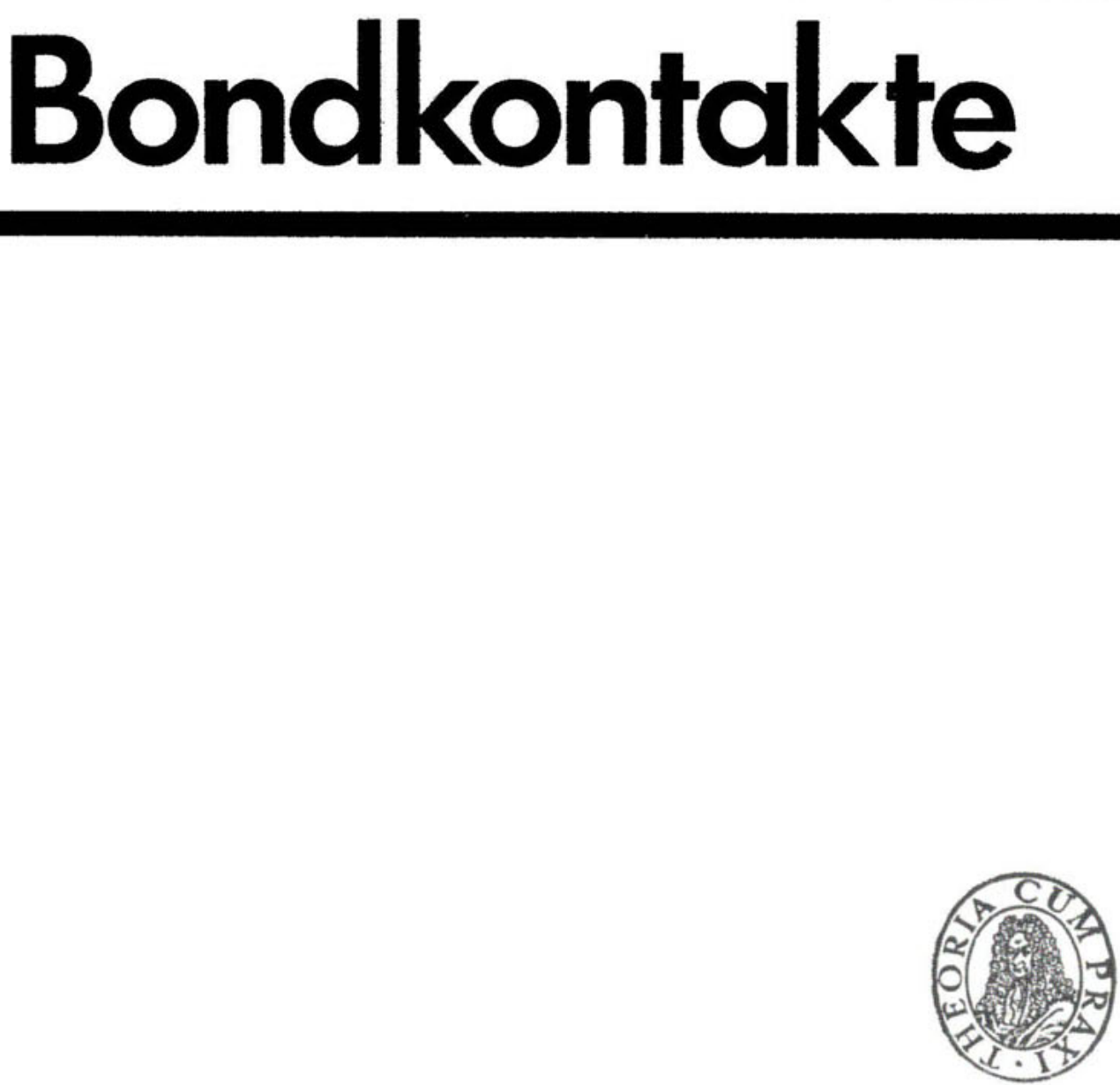

Akademie-Verlag Berlin 
In zwangloser Folge werden in dieser Form Arbeiten publiziert, die aktuelle Fragen des wissenschaftlich-technischen Fortschritts vornehmlich aus dem komplexen Wissenschaftsgebiet Mikroelektronik im weitesten Sinne behandeln.

Dabei ist schwerpunktmäßig zunächst an folgende Gebiete gedacht :

- Naturwissenschaftlich-technische Grundlagen, Wirkprinzipien, Werkstoffe und Technologie elektronischer Baueiemente und mikroelektronische Schaltkreise einschließlich Optoelektronik, Mikroakustik u. a.

- Entwurf mikroelektronischer Schaltungen,

- Anwendung der Mikroelektronik in produzierenden und nichtproduzierenden Bereichen der gesellschaftlichen Praxis, Mikroprozessortechnik, Hard- und Software von Mikrorechnern und Mikrorechnersystemen, einschließlich ihrer Peripherie sowie unter Beachtung der Sensoren-, Aktorenund Displayproblematik.

- physikalische Aspekte der CAD/CAM.

Die einzelnen Bände sind jeweils einem Thema gewidmet.

Der Verlag nimmt gern Anregungen für die Weitergestaltung der Bände entgegen. 